\title{
A PROMESSA DE CLÊNIO KARUAZU: HISTÓRIA E IMAGENS DA RELIGIÃO INDÍGENA NO SERTÃO DE ALAGOAS
}

\author{
JOSÉ ADELSON LOPES PEIXOTO ${ }^{1}$ \\ UNEAL, BRASIL \\ http://orcid.org/0000-0003-1047-7577
}

VINÍCIUS ALVES DE MENDONÇA ${ }^{2}$

UNEAL, BRASIL

https://orcid.org/0000-0002-1107-9688

\begin{abstract}
RESUMO: $O$ etnodocumentário "Promessa de Clênio Karuazu: por uma graça alcançada" foi gravado após o periodo que marcou o reconhecimento étnico dos indígenas da região sertaneja de Alagoas e apresenta cenas do cotidiano dos Karuazu, imagens inéditas àquela época. Visamos, através da análise da produção citada, realizar um estudo sobre a consolidação, pautada na religião, da imagem desses indígenas perante a sociedade e o Estado após terem sido reconhecidos. Metodologicamente, analisamos o etnodocumentário conforme autores como Ginzburg (1989), Candau (2016), Peixoto (2018) e Amorim (2017), embasando os estudos também nas experiências etnográficas sobre a religião proveniente do Tronco Pankararu, o qual originou os povos indígenas do Sertão de Alagoas (Jiripankó, Karuazu, Kalankó, Koiupanká, Katokinn e Pankararu), intercruzando as fontes durante o estudo da imagem religiosa dessas populações.
\end{abstract}

PALAVRAS-CHAVE: Etnodocumentário; Indígenas; Reconhecimento.

ABSTRACT: The ethnodocumentary "Promise of Clênio Karuazu: by a grace achieved" was recorded after the period that marked the ethnic recognition of the indigenous people of the outbacked region of Alagoas and presents scenes from the daily life of the Karuazu, images unpublished at that time. We aim, through the analysis of the aforementioned production, to conduct a study on consolidation, based on religion, of the image of those indigenous peoples before society and the State after they have been recognized. Methodologically, we analyzed the ethnodocumentary according to authors as Ginzburg (1989), Candau (2016), Peixoto (2018) e Amorim (2017), basing the studies also on the ethnographic experiences on religion from the Pankararu trunk, which originated the indigenous people of the outback of Alagoas (Jiripankó, Karuazu, Kalankó, Koiupanká, Katokinn e Pankararu), intersecting the sources during the study of the religious image of these populations.

KEYWORDS: Ethnodocumentary; Indigenous; Recognition.

\footnotetext{
${ }^{1}$ Doutor (2018) e Pós-Doutor (2020) em Ciências da Religião pela Universidade Católica de Pernambuco (UNICAP). Atualmente, é professor Adjunto da Universidade Estadual de Alagoas (UNEAL) onde coordena o Grupo de Pesquisas em História Indígena de Alagoas (GPHIAL) e Curso de Licenciatura Intercultural Indígena em História (CLIND-AL). E-mail: adelsonlopes@uneal.edu.br

${ }^{2}$ Graduando em História pela Universidade Estadual de Alagoas (UNEAL); integrante do Grupo de Pesquisas em História Indígena em Alagoas (GPHIAL) e bolsista voluntário no Programa Institucional de Bolsas de Iniciação Científica (PIBIC), financiado pela Fundação de Amparo a Pesquisa do Estado de Alagoas (FAPEAL). E-mail: viniciusalvesmendonca@,hotmail.com
} 


\section{Considerações iniciais}

No ano de 2018 , iniciamos nossas pesquisas entre os indígenas do Sertão de Alagoas realizando estudos sobre as pinturas corporais praticadas pelos Jiripankó. Com o aprofundamento das análises, nos deparamos com uma rede de relações, entre os grupos étnicos localizados em áreas próximas, pautada no compartilhamento de costumes, tendo em vista que as pinturas não são exclusivas aos Jiripankó, sendo também praticadas por outros como os Karuazu, Katokinn, Kalankó, Koiupanká e Pankararu, revelando uma espécie de religião comum, a qual suscitou a escrita desta produção.

As seis etnias possuem suas origens nas diásporas protagonizadas por indígenas Pankararu, saídos de Pernambuco, desde o século XIX, devido à Lei $n^{\circ} 601$ de 18 de setembro de 1850 (Lei de Terras) e a extinção, em 1875, do aldeamento "Brejo dos Padres", o qual habitavam desde que foram reunidos por missionários durante o Oitocentos (ARRUTI, 1996). Com as leis, Brejo dos Padres passou a ser invadido por fazendeiros e outros não-indígenas, condicionando os Pankararu a realizarem diversas diásporas com fins de sobrevivência (ARRUTI, 2004). Posteriormente, ocorreram novas migrações devido ao estabelecimento em outras regiões e estados (como Alagoas) e os convites direcionados aos que continuaram em Pernambuco.

Os primeiros a chegarem, conforme os registros (BRITO, 1992), foram, ainda no século XIX, os Pankararu que formaram os Jiripankó, primeiro grupo reconhecido na região sertaneja de Alagoas ${ }^{3}$. Após os citados, vieram os que deram origem aos Kalankó, Karuazu, Katokinn e Koiupanká, todos reconhecidos em 1999 (AMORIM, 2017). Por fim, no século XXI, migraram os que assumiram o etnômio Pankararu no município de Delmiro Gouveia.

As semelhanças, pautadas nos ancestrais vindos de Pernambuco através das diásporas, causaram uma maior afinidade entre esses povos, do mesmo modo que suas culturas apresentam elementos similares, considerando que são ressignificações dos costumes Pankararu dos séculos XIX e XX. Exemplos de tradições comuns entre os citados são os "Praiás"4 e os rituais que protagonizam, registrados e analisados pelo antropólogo Siloé Soares de Amorim durante seus 10 anos (1999-2009) de convivência, baseados na pesquisa etnográfica, entre tais indígenas.

Atualmente, o referido antropólogo é docente do departamento de Antropologia da Universidade Federal de Alagoas (UFAL), sendo uma das principais referências no estudo dos povos indígenas dos sertões de Alagoas e Bahia. Produziu e reuniu diversos documentos sobre essas populações, disponíveis no acervo do Antropologia Visual em Alagoas (AVAL), grupo de pesquisas que coordena, e em sua Tese de Doutorado publicada, em 2017, pelo Instituto do Patrimônio Histórico e Artístico

\footnotetext{
${ }^{3}$ Os Jiripankó protagonizaram reinvindicações desde meados dos anos 1980, tendo sido reconhecidos em 1992 (SANTOS, 2015).

4 Indígenas que realizam performances durante os rituais no sertão de Alagoas; utilizam vestes confeccionadas com fibras de Caroá, espécie de arbusto nativo da região, as quais encobrem seus corpos, deixando expostos apenas braços, pés e olhos, ocultando suas identidades sociais.
} 
Nacional (IPHAN), com o título Resistência e Ressurgência indígena no Alto Sertão alagoano.

Utilizamos enquanto fonte de pesquisa o etnodocumentário, produzido pelo citado pesquisador em 2001, intitulado Promessa de Clênio Karuazu: por uma graça alcançada, disponível na rede mundial de computadores. A produção retrata, em aproximadamente 30 minutos de gravação, o pagamento da promessa realizada por Clênio, indígena Karuazu, após receber uma benesse advinda da religião do seu povo ${ }^{5}$. Analisamos as etapas do ritual registrado, visando descrever o modo como o universo religioso compartilhado pelos indígenas do Sertão de Alagoas, marcado pelos seres "Encantados"6, contribuiu na consolidação dessas populações após os seus reconhecimentos.

Para a fundamentação teórica da pesquisa, nos apropriamos dos conceitos de Costume a partir de Peixoto (2018), Cultura conforme Laraia (2001) e Identidade segundo Candau (2016). Revisitamos, também, obras sobre os indígenas da região escritas por pesquisadores como Amorim (2017), Santos (2015), Barreto (2010) e outros. Na metodologia, seguindo o paradigma da Micro-história italiana (GINZBURG, 1989), optamos pela análise dos detalhes do etnodocumentário, utilizando suas cenas enquanto imagens ${ }^{7}$ e as interpretando à luz das experiências etnográficas, permeadas pelos conceitos de Oliveira (2000), obtidas em meio aos Jiripankó, também praticantes do pagamento de promessa documentado sobre os Karuazu.

\section{A retribuição da graça alcançada ao oferecer um "Prato"}

Nos início do etnodocumentário em questão é informado, através de um pequeno texto, que "As promessas indígenas, uma prática entre os Pankararu e seus descendentes, têm como finalidade agradecer uma graça alcançada aos Encantados, entidades espirituais que zelam pelo seu povo" (AMORIM, 2001). Com essa breve explicação, o espectador é introduzido no ritual exposto nas cenas seguintes, visto que o vídeo apenas registra a atividade através das imagens e sons do ambiente, não apresentando entrevistas que a expliquem ou descrevam suas particularidades, com exceção das poucas legendas entre algumas cenas.

A produção se encontra a mercê do público que a interpreta segundo a explicação inicial e as narrativas visuais apresentadas, incentivando, desse modo, o imaginário de quem a observa (SAMAIN, 2012). O evento registrado trata-se de um pagamento de promessa

\footnotetext{
${ }^{5}$ Os pagamentos de promessas são comuns entres os indígenas, representam um vínculo com a tradição e a retribuição de alguma benesse oriunda da religião indígena. Contam com a presença dos Praiás e outros indígenas, sendo realizados pela família do beneficiado e lideranças religiosas dos grupos a que pertencem. ${ }^{6}$ Seres cosmológicos que, segundo os indígenas, protegem os grupos étnicos e regem a religião. Cada Praiá representa um Encantado, não sendo as suas denominações, geralmente, reveladas a estranhos.

${ }^{7}$ As cenas do etnodocumentário foram adaptadas a esta produção enquanto imagens. Parar uma melhor análise, os minutos da gravação foram registrados nas legendas.
} 
indígena denominado "Prato", característico pela ação de oferecer um almoço aos Praiás em prol do agradecimento a alguma benesse recebida (MATTA, 2005).

Os primeiros 02:00 minutos do etnodocumentário são permeados pelo som das "Toantes" 9 marcadas pelo vínculo com a religião e o ritmo dos Maracás (HERBETTA, 2006). Em seguida, as gravações são realizadas por meio de aproximações e afastamentos da câmera, revelando detalhes do cotidiano Karuazu ao enfocarem aspectos como o ambiente e alguns indivíduos que conversam e/ou trabalham. O antropólogo registra o evento desde os preparativos até o encerramento, ambos essenciais para os indígenas, tendo em vista que envolvem

a comunidade em um conjunto de ações que vai da ajuda financeira à oferta de mão de obra nos preparativos. Após o pacto ser firmado, a dádiva deve ser concretizada mediante a fé no Encantado, nas suas habilidades e no seu poder. É uma relação de reciprocidade que coloca o Praiá e aquele que faz a oferenda em uma situação de troca, de harmonia (PEIXOTO, 2018, p. 141-142).

Oferecer um Prato ou realizar outros rituais apenas se torna possível em razão da parceria mútua da comunidade. Todos, desde as crianças até os idosos, contribuem de alguma maneira, seja financeira ou através do trabalho em alguma função, evidenciando a cooperação coletiva em prol do agradecimento pela dádiva (RODRIGUES; MENDONÇA, 2018). O Pajé (líder religioso) é um dos primeiros a contribuir "preparando" os elementos tradicionais ${ }^{10}$ que serão utilizados, conforme apresentado nas imagens a seguir.

Imagem 01: Processo de Defumação (02:03)

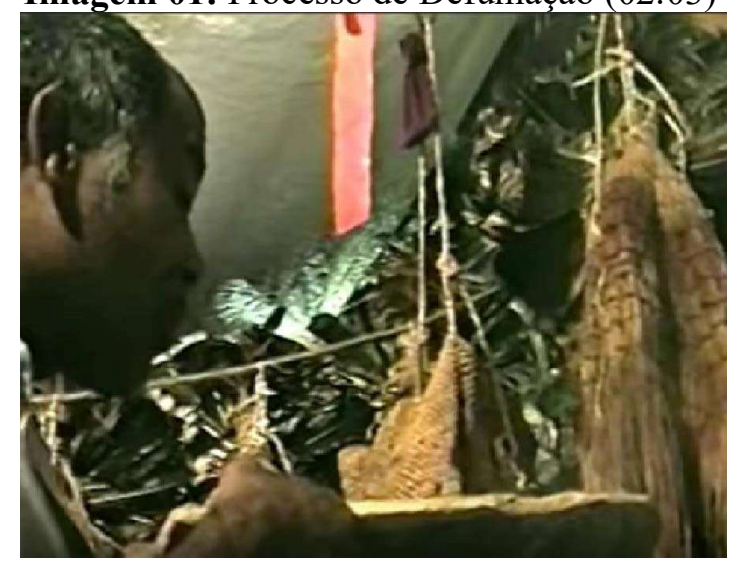

Fonte: Amorim (2001).

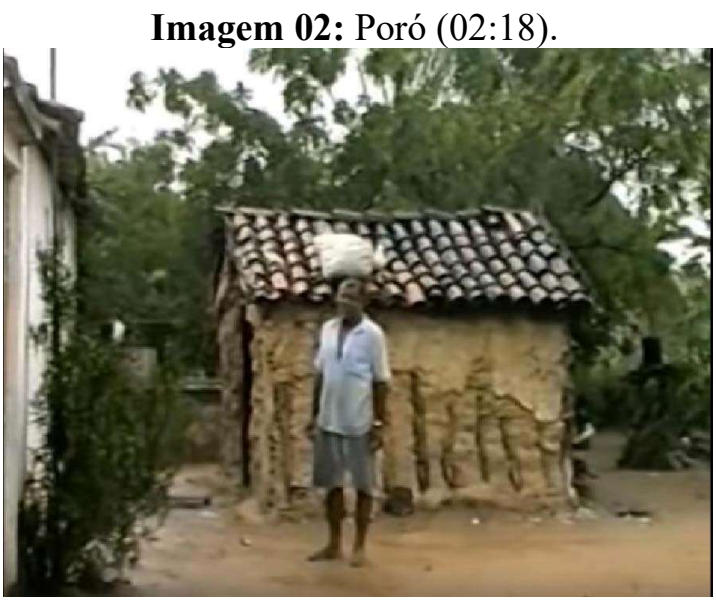

Fonte: Amorim (2001).

\footnotetext{
${ }^{8}$ Ritual caracterizado pela ação de oferecer um almoço aos Praiás simbolizando o vínculo com os Encantados e o pagamento de alguma promessa. No geral, é realizado em um final de semana escolhido pelo grupo e envolve vários indígenas nos seus preparativos.

${ }^{9}$ Cânticos realizados pelo grupo e ritmados pelos Maracás; ocorrem nos rituais e em seus preparativos, sacralizando o ambiente e possibilitando as relações com a religião.

${ }^{10}$ Os principais são as vestes dos Praiás, as quais necessitam ser "preparadas" através de processos rituais envolvendo fumaça e ervas tradicionais.
} 
Nas imagens 01 e 02 são exibidos os preparativos do ritual, iniciando pela primeira cena, denominada pelo autor das gravações como "Defumação". Nessa, o Pajé segura uma telha com algumas cinzas na sua superfície, essas que, ainda em brasa, geram a fumaça que é soprada sobre as vestes dos Praiás, penduradas por alguns fios de Caroá. A segunda cena evidencia o ambiente externo do Poró ${ }^{11}$, local onde ocorreu a Defumação citada. Esse processo religioso, envolvendo a fumaça, ocorre devido

Às pessoas que fazem promessas para aqueles encantados [e também] oferecem ervas e pau de cheiro que são misturados com fumo, colocados no campiô para fazer fumaça e defumar os praiás, contribuindo assim para os cuidados que os zeladores devem ter com essas máscaras rituais (MATTA, 2005, p. 85).

Seja com o Campiô (espécie cachimbo cônico) e as ervas ou com a telha e as cinzas, a fumaça é vinculada aos cuidados que os Zeladores ${ }^{12}$ têm com os Praiás, servindo "para defumar e isso retira as energias negativas e funciona como portal [entre] a terra e o mundo cosmológico dos Encantados" (PEIXOTO, 2018, p. 76). Tais zelos ocorrem no Poró, local onde as máscaras são guardadas, podendo ser desde uma estrutura de palha até uma pequena casa. Geralmente, o local da imagem 02 é utilizado para guardar as vestes e o outro, apresentado na imagem a seguir, serve de abrigo para os Praiás durante os rituais. Ambos possuem normas de circulação, pois apenas os indígenas do sexo masculino podem entrar nesses espaços (RODRIGUES; MENDONÇA. 2018).

Imagem 03: Preparações do ritual (02:27).

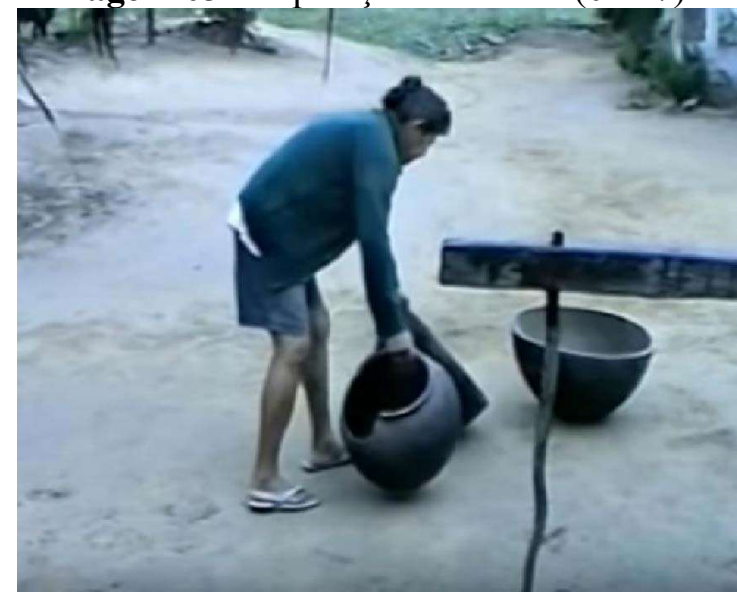

Fonte: Amorim (2001).
Imagem 04: Poró do Terreiro (02:30).

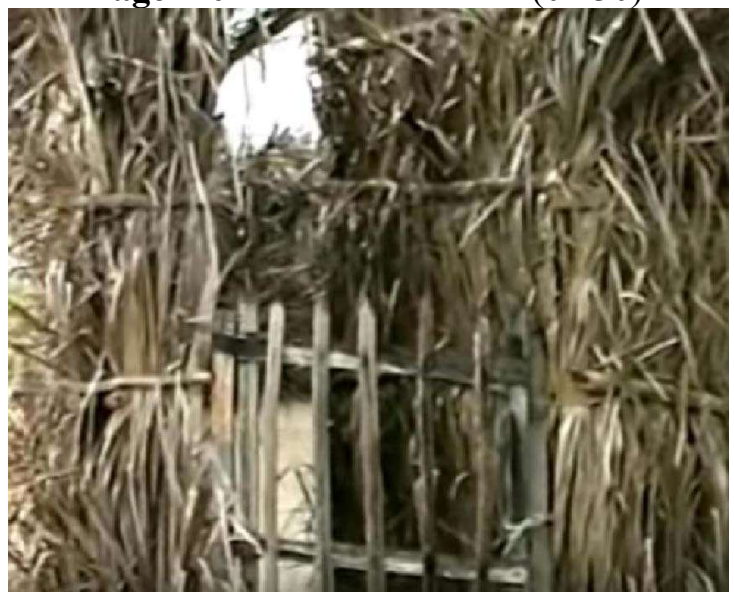

Fonte: Amorim (2001).

Seguindo a perspectiva de suscitar interpretações do espectador, as cenas das imagens 03 e 04 expressam mais aspectos preparativos. A

\footnotetext{
${ }^{11}$ Local onde os indígenas guardam as vestes rituais e realizam as etapas íntimas do ritual; é denominado, também, de "Casa dos homens" em função das regras de circulação, pois apenas indígenas do sexo masculino podem entrar no seu espaço.

${ }^{12}$ Lideranças religiosas que detém um grande conhecimento das tradições e são responsáveis pelos cuidados com as vestes dos Praiás antes e durante os rituais.
} 
primeira registra o trabalho feminino pautado em separar os potes e tigelas de barro que serão utilizados no preparo dos alimentos, servidos ao público no ápice do evento; a segunda revela a entrada do Poró do "Terreiro"13 utilizado pelos Praiás para realizarem os cultos íntimos e descansarem durante o ritual.

Retornando a câmera ao primeiro Poró, é filmado um novo processo de Defumação, esse com o Campiô. Em silêncio, um dos indígenas realiza sopros com o cachimbo, expelindo novamente fumaça sobre as vestes e o ambiente, existindo ao fundo um pequeno "altar" com imagens de santos da Igreja Católica Romana ${ }^{14}$. Finalizado o processo, o indivíduo caminha pelo local ritmando seu Maracá e cantando uma Toante em som reduzido; segura, ainda, um pequeno copo com algum líquido não identificado, cenas que apresentamos a seguir:

Imagem 05: Defumação com o Campiô $(02: 36)$

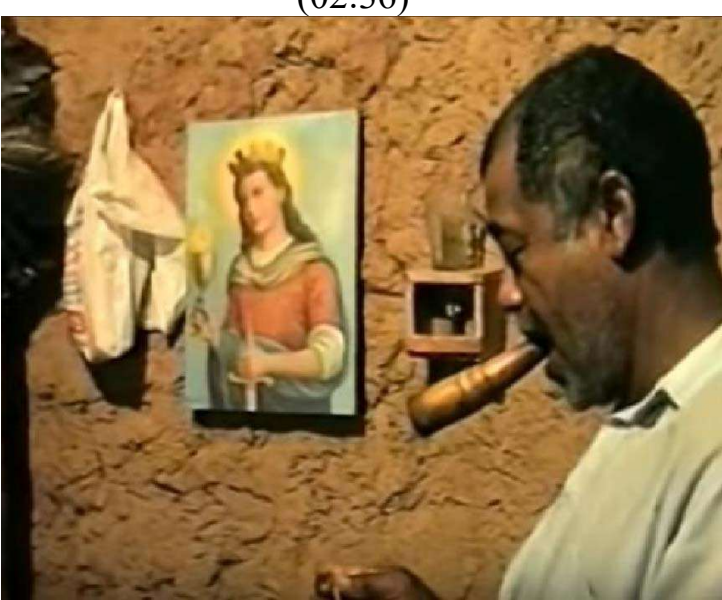

Fonte: Amorim (2001)
Imagem 06: Altar (03:57).

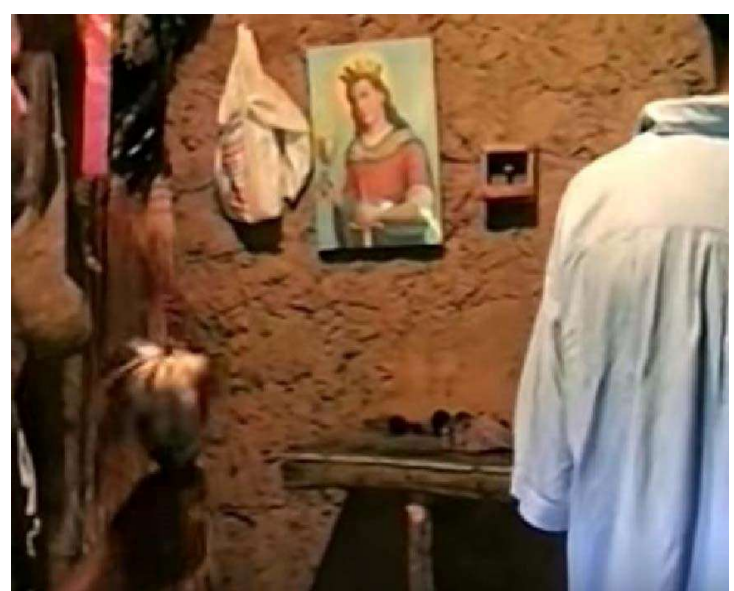

Fonte: Amorim (2001)

Não é comum, entre os povos indígenas do Sertão, o acesso de estranhos ao ambiente apresentado nos registros acima. O Espaço do Poró é restrito e carregado de significados, estando presente entre os seis povos da região. Devido à convivência, através da etnografia, o Antropólogo Siloé Amorim pôde, de modo inédito, registrar essas imagens e esboçar o conceito, por ele denominado, de "fabricação da imagem étnica" (AMORIM, 2017).

Distante de afirmar que os indígenas "inventaram" suas identidades no processo de reconhecimento (1992-1999) ou passaram as "encenar" após a década de 1990, o que é proposto, através do conceito de fabricação a imagem, é a compreensão do modo como esses povos se reorganizaram a partir de elementos culturais oriundos dos Pankararu ancestrais, protagonizando processos de emergência étnica, embasados principalmente na religião praticada (AMORIM, 2017; OLIVEIRA, 2004).

\footnotetext{
${ }^{13} \mathrm{O}$ Terreiro é um grande espaço retangular, com cerca de 20 metros, onde ocorrem as etapas públicas dos rituais; não possui construções ou vegetações em seu meio, sendo marcado pelo soro arenoso. O Poró do Terreiro é o local onde os Praiás descansam e realizam as atividades íntimas da tradição.

${ }^{14} \mathrm{Em}$ função do contato com a Igreja, diversos símbolos e particularidades cristãs foram ressignificados pelos indígenas, principalmente durante o aldeamento em Brejo dos Padres e os silenciamentos nas diásporas.
} 
A etapa seguinte à Defumação com o Campiô, registrada nas imagens anteriores, é o preparo dos alimentos servidos no ritual, desenvolvido de forma separada entre os sexos, pois os homens cortam as partes da carne e as mulheres preparam o que recebem dos primeiros, momentos apresentados nas imagens a seguir.

Imagem 07: Corte das carnes (04:43).

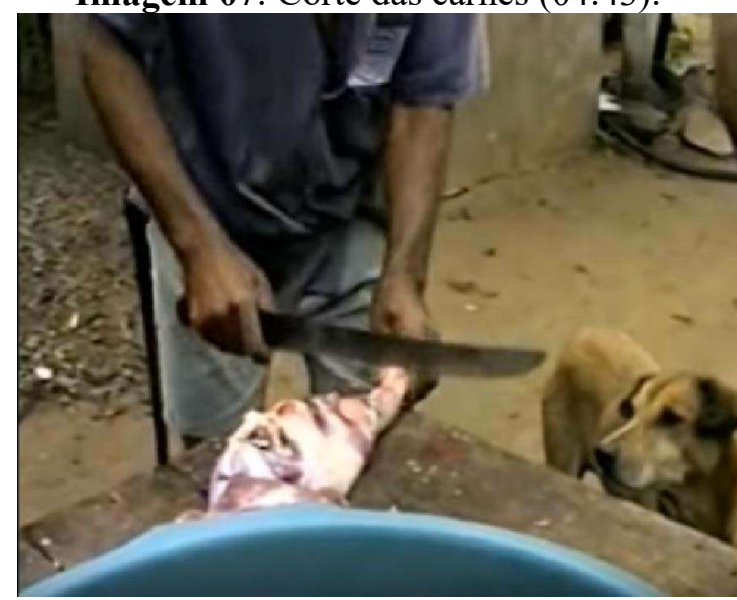

Fonte: Amorim (2001).
Imagem 08: Preparo das carnes (05:36).

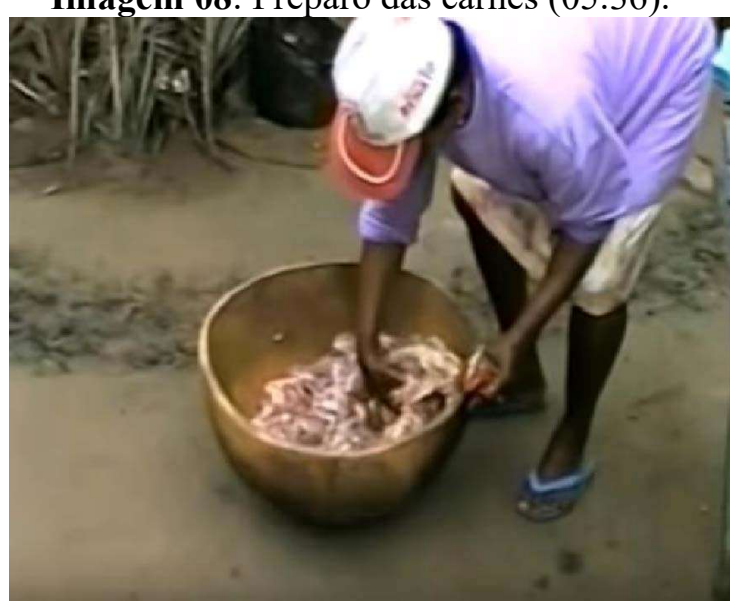

Fonte: Amorim (2001).

Grandes tigelas de barro e algumas bacias de plástico servem como recipientes no preparo. Após serem cortados pelos homens, os pedaços da carne são entregues às mulheres que os temperam para, em seguida, serem cozidos no fogão a lenha. No caso específico da promessa de Clênio, uma ovelha foi abatida, mas os animais podem variar entre bois, porcos, peixes, cabras ou espécies nativas da Caatinga. A opção depende da condição financeira do pagante da promessa e da escolha do Encantando ${ }^{15}$ (MATTA, 2005).

\section{O Terreiro da promessa e a saída dos Praiás}

Enquanto a ovelha estava sendo preparada, outras atividades foram realizadas a fim de evitar atrasos, tendo em vista a importância dos horários nos rituais indígenas no Sertão. Geralmente, iniciam pela manhã e finalizam ao por do sol, devendo todas as etapas do evento se enquadrarem nesse recorte temporal. Assim, de modo concomitante ao preparo dos alimentos, o Pajé e alguns Cantadores ${ }^{16}$ realizam a Defumação do Terreiro; o circundam, expelindo a fumaça pelos seus Campiôs e marcando o ritmo com um Maracá, momento representado a seguir.

\footnotetext{
${ }^{15} \mathrm{O}$ processo de escolha do alimento pelo Encantado ocorre de forma intima na tradição. Geralmente, o momento é intermediado pelas lideranças religiosas, sendo, como outros, restrito a terceiros.

${ }^{16}$ Personagens responsáveis pelas Toantes.
} 
Imagem 09: Pajé e Cantadores (06:10).

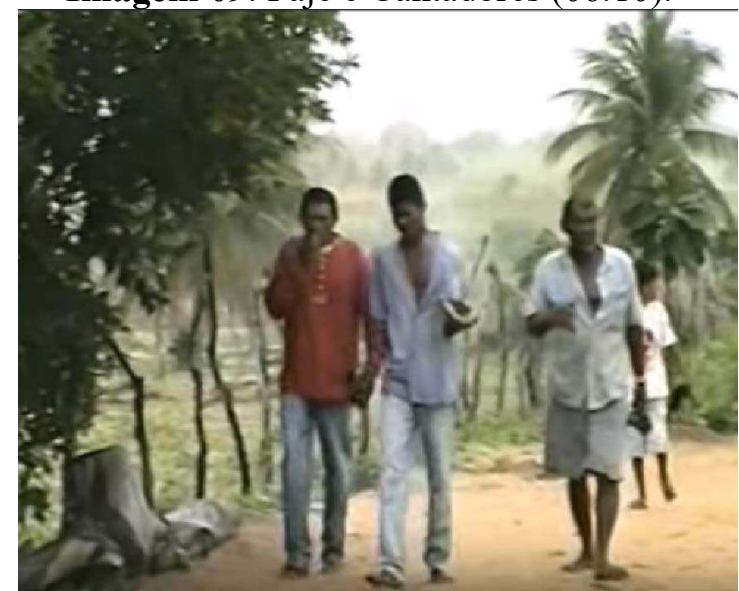

Fonte: Amorim (2001).
Imagem 10: Toante no Poró (06:45).

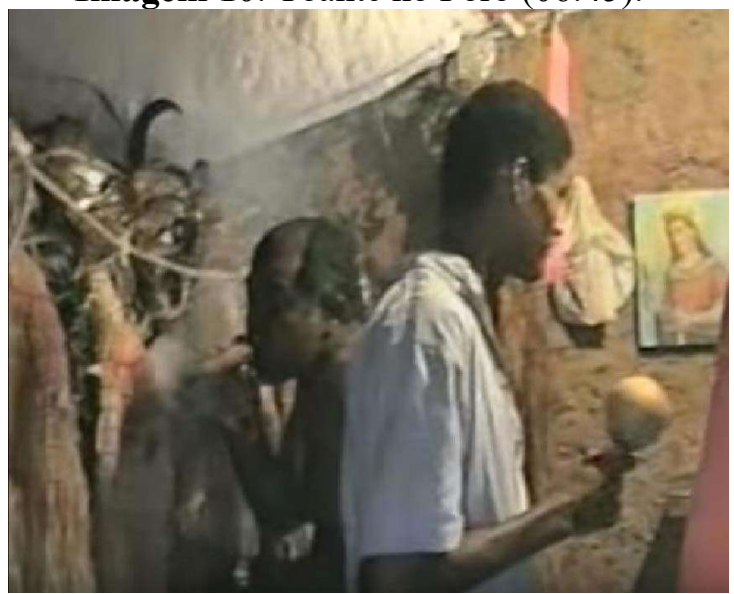

Fonte: Amorim (2001).

Notamos, na imagem 09, o solo arenoso do Terreiro sobre o qual os indígenas caminham carregando uma telha com cinzas (sujeito ao centro) e fumando nos Campiôs (indivíduos à direita e a esquerda); são acompanhados por algumas crianças ao fundo. Os três percorrem o local, com os pés descalços, e retornam ao Poró onde entoam algumas Toantes e defumam novamente as vestes dos Praiás, conforme registrado na imagem 10.

Uma característica comum entre os povos do Sertão alagoano se refere ao protagonismo nas atividades. Os Pajés são os líderes religiosos dos grupos, contudo, por vezes, cedem o lugar a outros indígenas para que esses realizem atividades centrais, como exemplificado nas imagens 09 e 10 em que o líder se encontra, na primeira, à direita de outro indígena e, na segunda, atrás do responsável por "puxar" a Toante. Não necessariamente o Pajé precisa reger toda a atividade, sua presença, de fato, é importante, mas outros também coordenam alguns momentos, sendo esses participantes Mestres da tradição ou Cantadores (PEIXOTO, 2018).

Enquanto defuma os Praiás (imagem 10), o líder religioso realiza discretos movimentos em forma de "cruz" com o seu Campiô, conferindo ainda mais sacralidade às vestes. O uso da cruz em diversos suportes (pinturas corporais, Praiás, Campiôs, gestos, etc.) é resultante do sistema de "aproximações" e "afastamentos" protagonizados pelos indígenas frente à religião Católica Romana.

Em alguns períodos das suas histórias, os grupos étnicos tiveram contatos (aproximações) com a Igreja, inicialmente no aldeamento Brejo dos Padres, criado por missionários, e depois nas diásporas. Nesses processos, passaram a adotar símbolos cristãos como forma de sobrevivência (SANTOS, 2015). Posteriormente, na segunda metade do século XX, se intensificaram os "afastamentos" baseados na distinção dos diacríticos indígenas frente aos não-indígenas (POMPA, 2011), caracterizando as atuais identidades dessas populações.

Em ambos os processos, particularidades, inicialmente opostas, foram associadas, a exemplo da cruz cristã, que foi vinculada aos Encantados indígenas, originando, com os ressurgimentos (AMORIM, 
2017), as autoafirmações baseadas no principio da diferença e na ressignificação dos elementos estranhos, conferindo-lhes novo significado (PEIXOTO, 2018).

Ainda no ritual, finalizada a Defumação, feita pelo Pajé, os indígenas pegam as vestes dos Praiás e as levam para o Poró do Terreiro. Uma Toante foi cantada enquanto seguiam em fila indiana segurando as "fardas"17, cena apresentada a seguir:

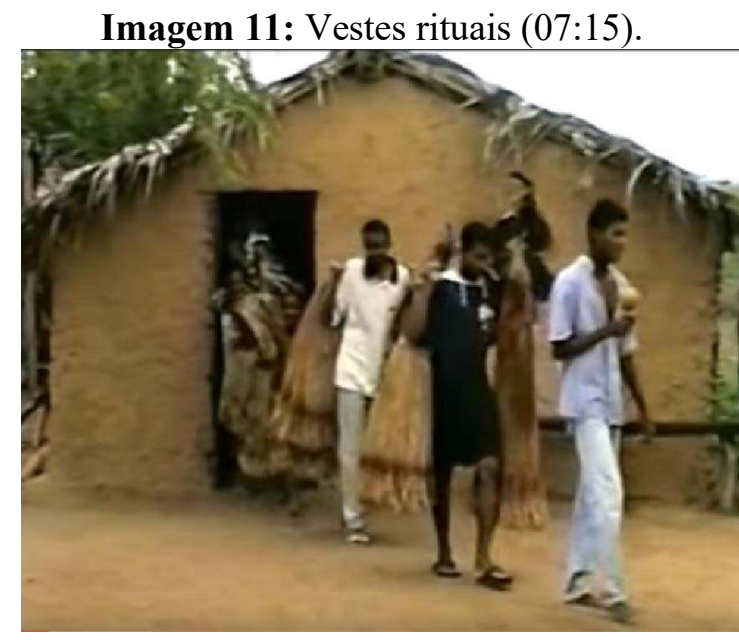

Fonte: Amorim (2001).

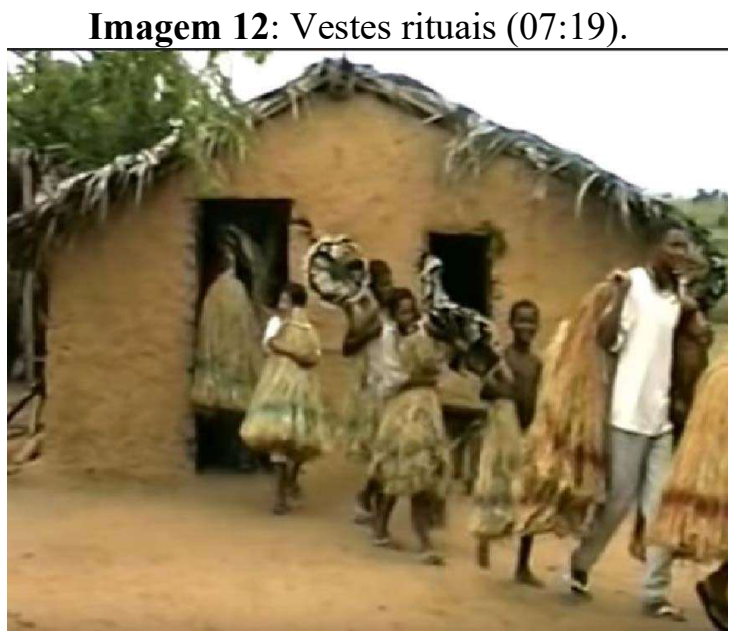

Fonte: Amorim (2001).

$\mathrm{Na}$ frente do cortejo se encontra o Cantador, seguido pelos demais indígenas que carregam as fardas. Destacam-se as crianças que ajudam na atividade. Essas e os adultos são exclusivamente do sexo masculino, pois "as mulheres são impedidas de participar dos rituais no poró, nos quais se exige a presença somente dos homens" (MURA, 2015, p. 170). Após levarem as vestes, dançam Toré no Poró construído na borda do Terreiro e entoam algumas Toantes.

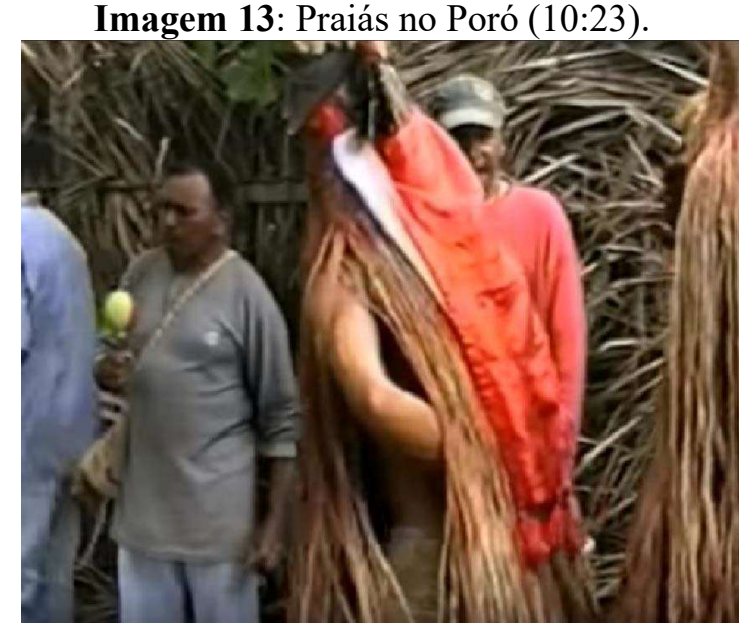

Fonte: Amorim (2001).
Imagem 14: Saída do Poró (11:02).

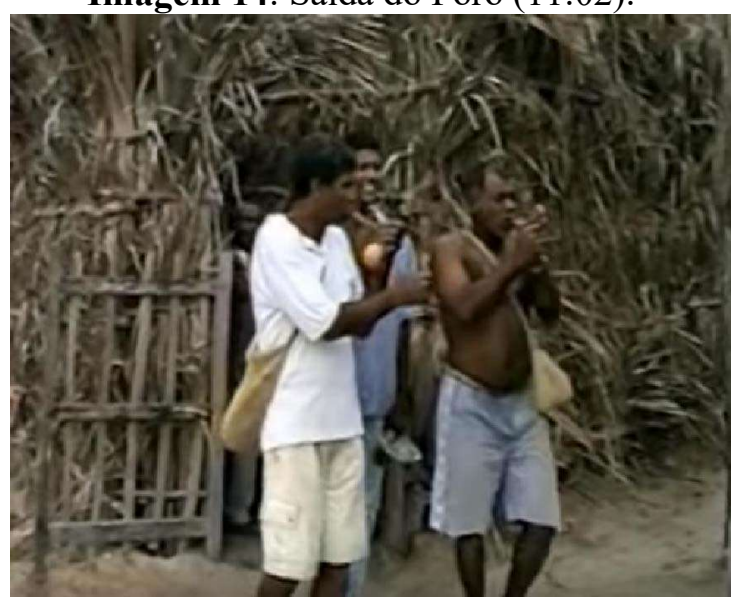

Fonte: Amorim (2001).

\footnotetext{
${ }^{17}$ Vestes, fardas ou roupões são denominações utilizadas pelos indígenas em referência às indumentárias
} dos Praiás. 
Terminadas as etapas descritas, o ritual é iniciado com a saída dos indígenas trajando as vestes de Caroá, contexto em que os Praiás, principais representantes dos indígenas do Sertão, se apresentam. Nos momentos seguintes, o Cantador coordena o ritmo e os Praiás se organizam em fila para se dirigem ao Terreiro, os últimos respondem à Toante cantada pelo primeiro através de alguns sons característicos e pisadas firmes no chão.

O Praiá "se revela" ao ocultar a identidade de quem veste a farda, existindo uma relação ambígua entre as identidades dos indígenas e dos Praiás, tendo em vista que, "embora a identidade dos moços ${ }^{18}$ precise manter-se oculta, são os zeladores que se expõem e todos sabem por quais encantados eles zelam" (MURA, 2015, p. 306). Apesar de não se saber a identidade social de quem utiliza a veste, esses representam Encantados específicos e os Zeladores os identificam através das cores e símbolos da Cinta ${ }^{19}$.

Os Cantadores lideram a fila na saída do Poró (imagem 14), sendo seguidos pelos moços vestidos. Todo o cortejo se desloca rumo ao Terreiro sob o som das Toantes, Maracás e Gaitas ${ }^{20}$. Após a entrada no espaço do ritual, os responsáveis pela coordenação dos ritmos passam a realizar seus papéis, enquanto apenas os Praiás circulam em meio ao Terreiro; nesse momento

A fronteira, existente nos espaços sagrados do ritual, não é ultrapassada $[\ldots]$, pois o conjunto de regras e interdições servem de limites. Assim, os lugares de memórias, que erguem uma linha imaginária divisória entre o mundo do índio e não-indígena, são fatores que mantem os segredos do sagrado da sociedade indígena e fortalece o sentimento de pertencimento já que a identidade é plenamente relacionada às práticas religiosas da comunidade (GUEIROS, 2017, p. 59).

Assim, descrever as etapas do ritual e compreender as funções dos Praiás - principalmente no Terreiro - são exercícios para além do factualíssimo, pois contribuem no entendimento dos lugares sociais das seis etnias do Sertão alagoano. Os momentos no Terreiro representam a fronteira da identidade dos indígenas durante e após os ressurgimentos (AMORIM, 2017). Essa fronteira é resultado de um longo processo histórico ilustrado no gráfico a seguir, elaborado com os principais marcos temporais na cronologia histórica dos grupos.

\footnotetext{
${ }^{18}$ Referência aos jovens indígenas que vestem as indumentárias dos Praiás; suas identidades não podem ser reveladas ao público.

19 Tecidos coloridos que se encontram nas costas do Praiá, possuem símbolos como cruzes, animais e, até mesmo, palavras que fazem referência aos Encantados.

${ }^{20}$ Flautas utilizadas para reproduzir sons semelhantes aos de pássaros; complementam as Toantes e são tocadas pelos Praiás com o intuito de sacralizar a atividade.
} 
Gráfico 1: Cronologia dos povos indígenas do Sertão de Alagoas.

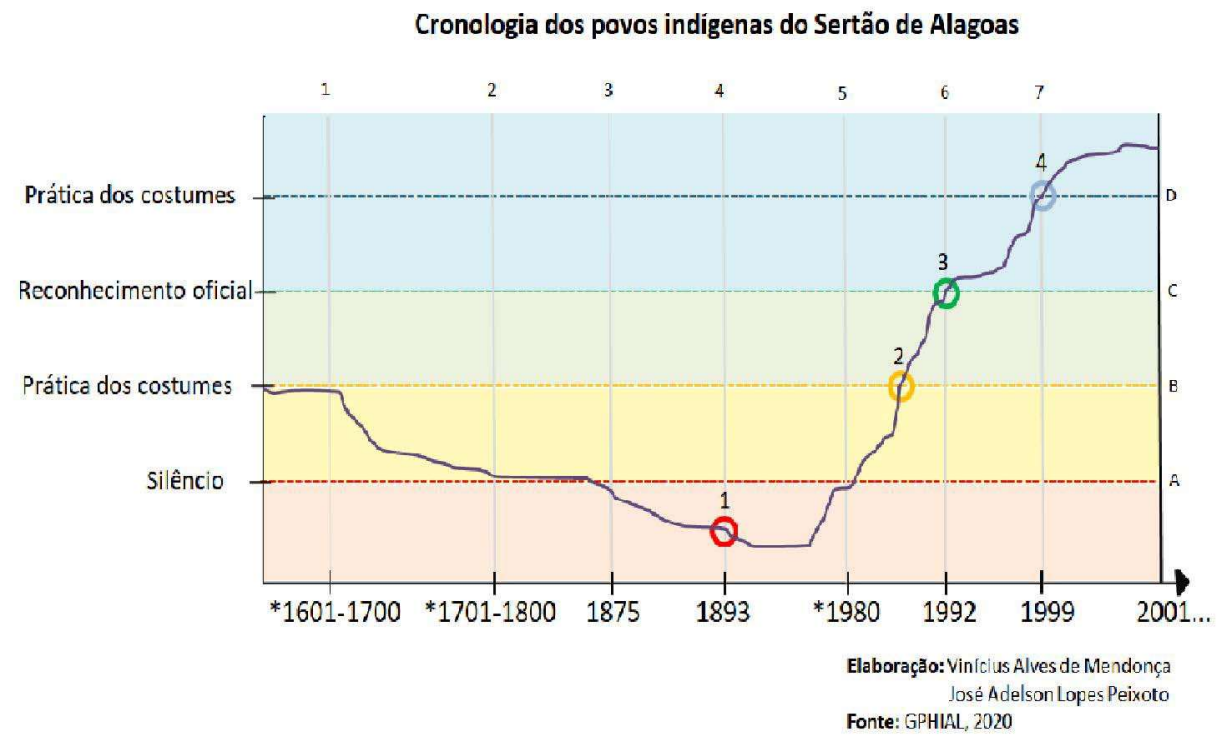

Fonte: Gráfico elaborado pelos autores a partir dos dados do Grupo de Pesquisa em História Indígena de Alagoas (GPHIAL, 2020).

A partir das primeiras "aproximações", entre os Séculos XVII e XVIII (PEIXOTO, 2018), os indígenas começaram a diminuir a prática dos seus costumes, em função da convivência com os missionários cristãos, chegando à condição de silêncio, principalmente após 1875 , ano da extinção dos aldeamentos. Nesse sentido, a cronologia ilustrada inicia com a prática dos costumes e decai em direção ao silêncio, pois esse foi uma das táticas adotadas pelos, à época, Pankararu com o objetivo de sobreviver às perseguições e invasões (SANTOS, 2015).

Em 1893, conforme ilustra o círculo 1 do gráfico, ainda no período de silêncio, os Pankararu chegaram ao município de Pariconha, os primeiros foram José Antônio do Nascimento (Zé Carapina) e sua esposa Isabel (BRITO, 1992; PEIXOTO, 2018); esses e outros que migraram, continuaram a ocultar seus costumes em solo alagoano. Contudo, em meados dos anos 1980, os descendentes dos primeiros que chegaram, iniciaram processos de reorganização ${ }^{21}$ e retomaram as práticas dos costumes (marcação circular 2 do gráfico) através das idas a Brejo dos Padres e vínculos com os Pankararu (GUEIROS, 2017).

A consequência desse processo se deu nos anos de 1992 e 1999 (marcações circulares 3 e 4 do gráfico), momentos em que os povos indígenas da região sertaneja de Alagoas foram reconhecidos. Propositalmente, destacamos, na ilustração do gráfico anterior, dois períodos referentes à prática dos costumes; o primeiro representa as tradições antes das aproximações e o segundo equivale aos momentos após os reconhecimentos - registrados no etnodocumentário analisado -

\footnotetext{
${ }^{21}$ As diásporas e o silêncio afetaram a organização social dos grupos étnicos, sendo necessário, durante os ressurgimentos, que esses se reorganizassem enquanto retomavam a prática dos costumes tradicionais (AMORIM, 2017).
} 
responsáveis pela consolidação da imagem dos indígenas através das aparições e rituais (AMORIM, 2017).

Tal opção pela separação da prática dos costumes em dois recortes temporais se deu em razão das culturas Jiripankó, Kalankó, Karuazu, Katokinn, Koiupanká e Pankararu, constituídas por elementos como os Praiás, Toantes, pinturas corporais e rituais, serem ressignificações dos Pankararu que os formaram, pois

após o início dos movimentos reinvidicatórios, esses elementos, tanto os aceitos quanto os coibidos, precisaram ser ressignificados de modo a responder as demandas classificatórias confirmando: Somos filhos de Pankararu! [...] eles criam novas etnias, filhas dos Pankararu, as ramas, que tem no tronco um passado seguro, mas que também possuem sua autonomia enquanto novas etnias. Dessa forma, ao buscarem laços ancestrais, esses sujeitos passaram a se sentir pertencentes a um passado, que revivido no presente, torna-se um novo conjunto de elementos (BARRETO, 2010, p. 58).

Assim, a promessa de Clênio Karuazu, enquanto uma espécie de laço com a ancestralidade buscada pelos indígenas, contribuiu na consolidação desses grupos étnicos. O evento cumpriu sua função representando o passado e desenhando o futuro dos indígenas. Nesse sentido, a aparição dos Praiás na atividade e o passado ancestral (século XVIII) são dois momentos, segundo os membros dos povos, associados, mas com particularidades e intenções que lhes são próprias, justificando a separação.

Os Praiás e outros costumes potencializaram, após os reconhecimentos, a imagem dos indígenas, de modo que a sua presença no Terreiro, destacada nas imagens a seguir, é o resultado da sua história, intenções e reivindicações.

Imagem 15: Praiás no Terreiro (11:55).

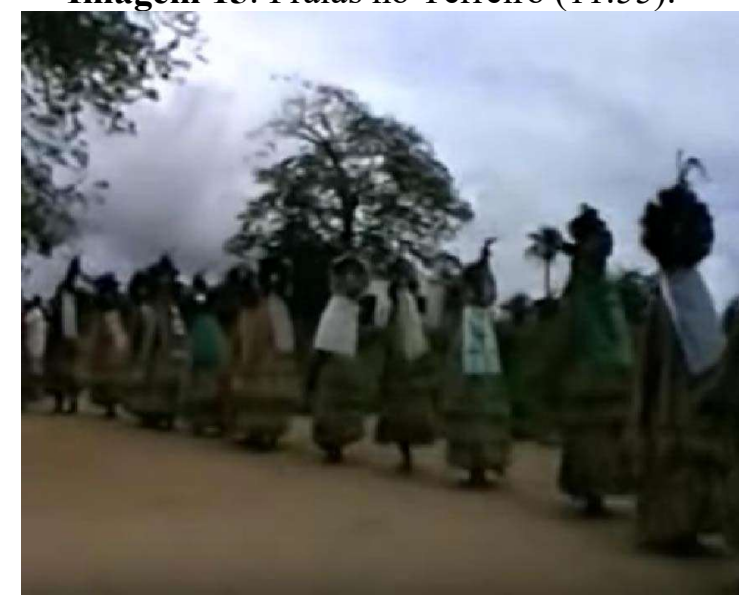

Fonte: Amorim (2001)
Imagem 16: Praiás em "Pareia” (12:28).

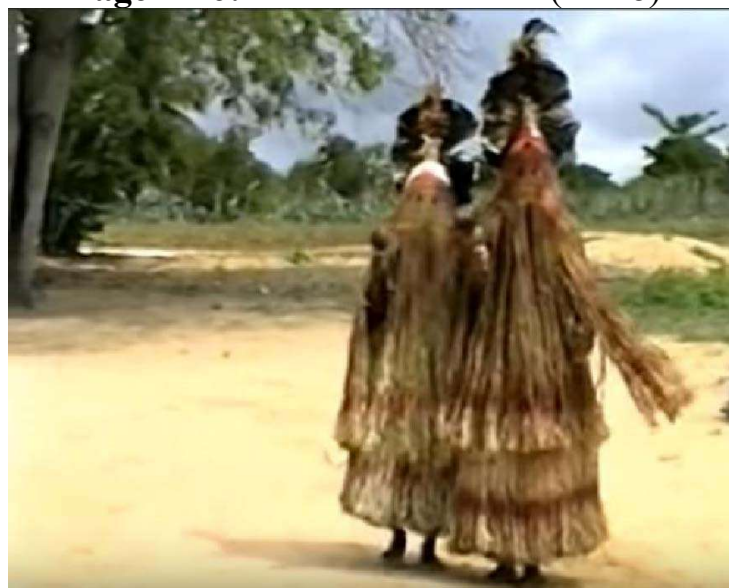

Fonte: Amorim (2001). 
Em ambos os registos, o Antropólogo, autor das gravações, enfocou o comportamento dos protagonistas do ritual. Eles cantam e circundam o Terreiro, ritmando o caminhar através dos Maracás e Toantes do Cantador. Na maior parte do tempo, organizam-se em fila indiana, ficando alguns momentos em duplas para realização da dança denominada "Pareia", momento em que circulam o Cantador e cantam a Toante do momento em alto tom; mantem-se, nessas condições, a espera do almoço servido pelo pagante da promessa.

\section{O Almoço servido e a reciprocidade frente aos Praiás}

O oferecimento do Prato é um ritual pautado no princípio da reciprocidade, uma vez que, os Encantados, representados pelos Praiás, concedem as benesses aos indígenas e esses, por sua vez, retribuem o que lhes foi concedido através desse evento. Assim, "a coisa recebida não é inerte. Mesmo abandonada pelo doador, ela ainda conserva algo dele" (MAUSS, 1974, p. 198), criando, desse modo, a obrigatoriedade de retribuição da dádiva, a fim de conservar o vinculo com a religião.

Em algum momento da sua vida, a depender da sua condição financeira, tendo em vista que os eventos religiosos envolvem um capital considerável nos seus preparativos, o indígena beneficiado deverá "pagar" a sua promessa realizando algum ritual, como foi o caso de Clênio e o prato ofertado aos Praiás em 2001. Nessa atividade, a reciprocidade entre indígenas e Encantados foi concretizada, principalmente nos contextos das imagens a seguir.

Imagem 17: Preparo dos Pratos (15:35).

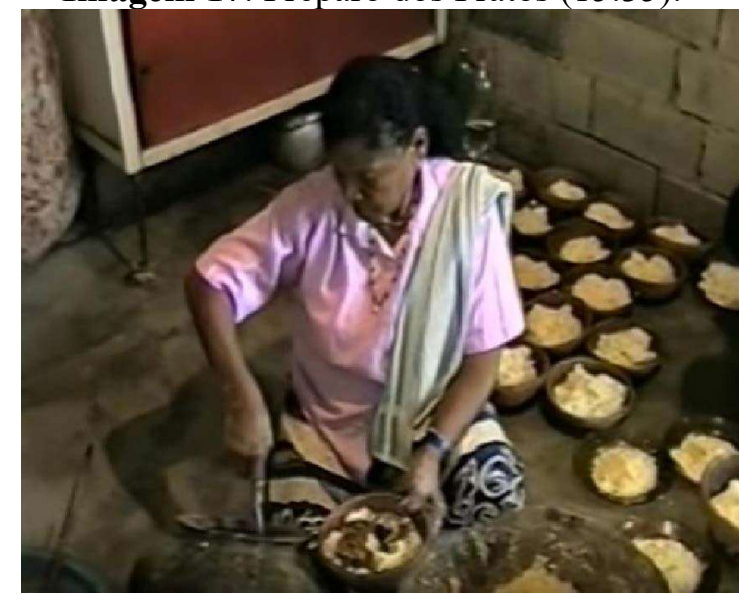

Fonte: Amorim (2001).
Imagem 18: Distribuição dos Pratos (16:18).

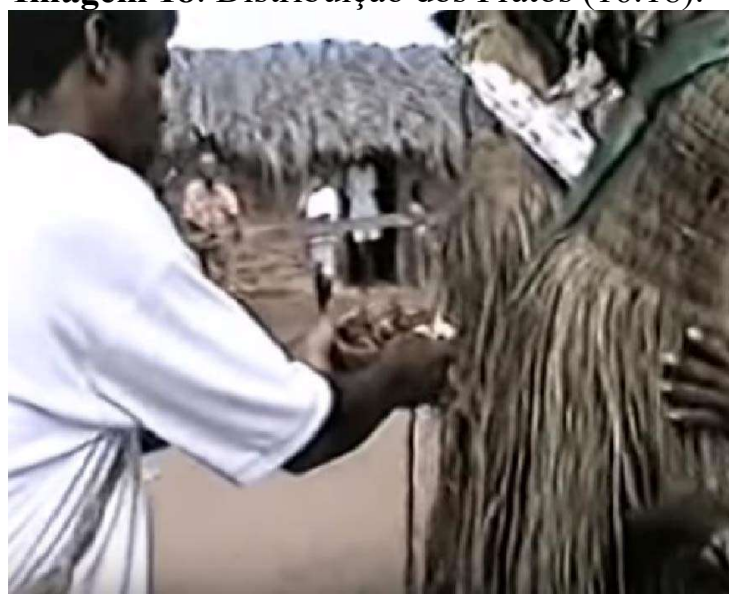

Fonte: Amorim (2001)

As mulheres finalizam o preparo da refeição (imagem 17) em tigelas de barro onde colocam farinha de mandioca misturada ao caldo da carne que foi cozida, complementando com alguns pedaços do cordeiro. Enquanto isso, no Terreiro, o ritmo das Toantes é alterado e os Praiás começam a se preparar para receberem o almoço ofertado. Esses se deslocam rumo a uma das casas próximas e recebem, das mãos de Clênio, o alimento (imagem 18). 
Apesar do trabalho coletivo, não são diversos indígenas envolvidos no ápice do evento, momento que é protagonizado de modo individual (MURA, 2015), pois o pagante da promessa necessita afirmar seu vínculo e agradecimento através do contato direto com os representantes dos Encantados. Nesse sentido, o próprio Clênio realiza a entrega dos pratos a cada um dos muitos Praiás.

Com a refeição em mãos, Pajé, Cantadores e Praiás se dirigem ao Poró do Terreiro, sob o som das Gaitas, local onde se alimentarão. Após o almoço, durante o descanso dos Praiás, os indígenas preparam a indumentária que utilizarão no Toré realizado no Terreiro; pintam-se com um barro de coloração branca (MENDONÇA, 2019) e vestem saiotes de palha. O momento da dança coletiva envolve as lideranças religiosas e outros membros da comunidade; festejam em agradecimento e realizam a transição para a etapa final do ritual.

Imagem 19: Toré coletivo (17:30).

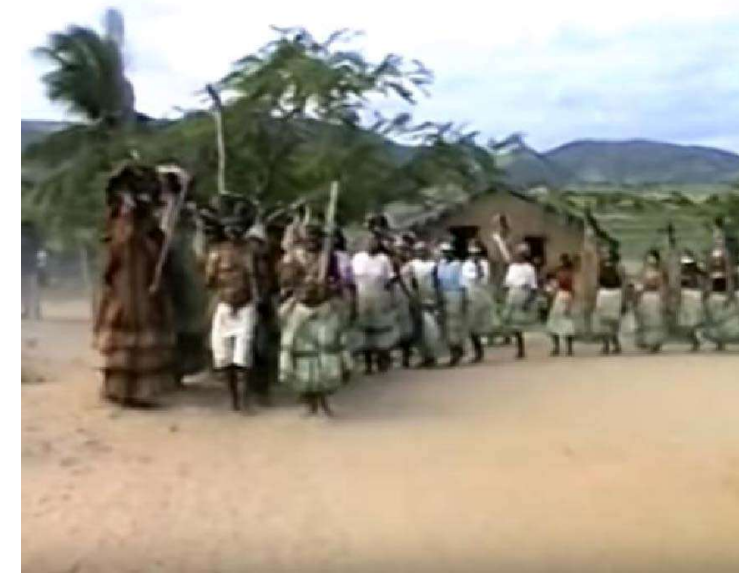

Fonte: Amorim (2001).
Imagem 20: Toré coletivo (19:11).

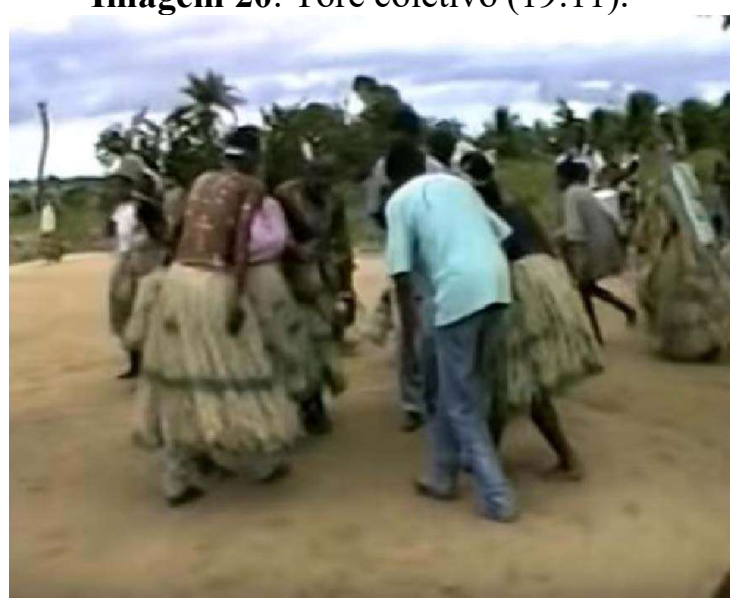

Fonte: Amorim (2001).

O Toré, registado nas imagens 19 e 20, é marcado por agradecimento e festejo, contudo não caracteriza o ápice do evento, pois trata-se de um costume consolidado, principalmente, pela influência de órgãos como o Sistema de Proteção aos Índios (SPI), enquanto esteve em exercício (1910-1967), e a Fundação Nacional do Índio (FUNAI), desde sua criação em 1967, enquanto diacrítico indígena no Nordeste. Nesse sentido,

parece estar despido da carga sagrada infundida ao resto do ritual, o que permite que seja 'apresentado' em diversos contextos. Fora do terreiro ou até da própria aldeia, os Pankararu [e suas ramas] podem [...] dançar toré em circunstâncias e lugares em que é preciso mostrar a própria identidade étnica diante de um público que assim o solicite ou para afirmar a sua presença em um contexto como forma de reivindicação (MURA, 2015, p. 292).

Assim, em razão do processo final de sacralização, os dançadores do Toré cedem lugar aos Praiás, Cantadores, Pajé e pagante da promessa, 
pois existe a necessidade de que os proponentes do ritual possam manter e intermediar as relações de reciprocidade entre o humano e o sagrado, momento descrito por Siloé Amorim como "no final da tarde, o pagador da promessa é encruzado (consagrado) pelo 'batalhão' dos Praiás e pelos mestres de Toré, Pajé e Cacique. O terreiro é fechado e os Praiás voltam para a casa dos “homens encantados'” (AMORIM, 2001). A seguir apresentamos as imagens desta etapa.

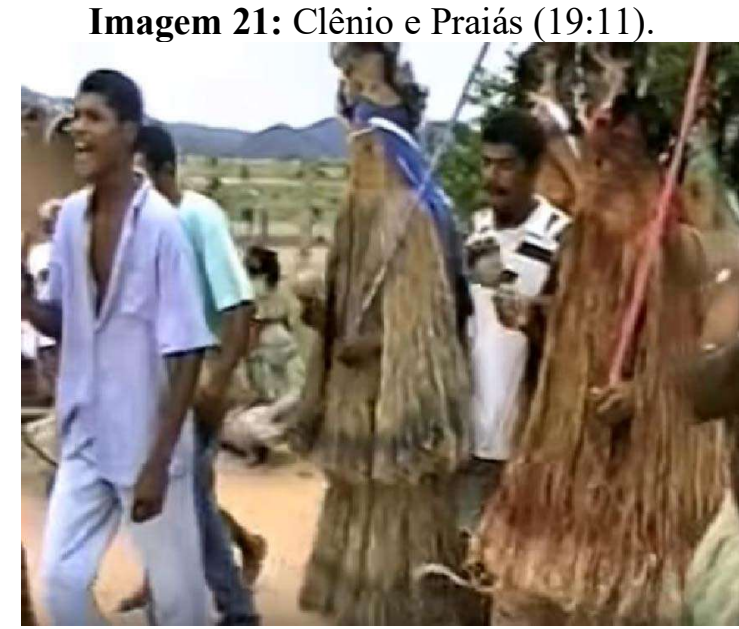

Fonte: Amorim (2001).
Imagem 22: Defumação de Clênio (22:18).

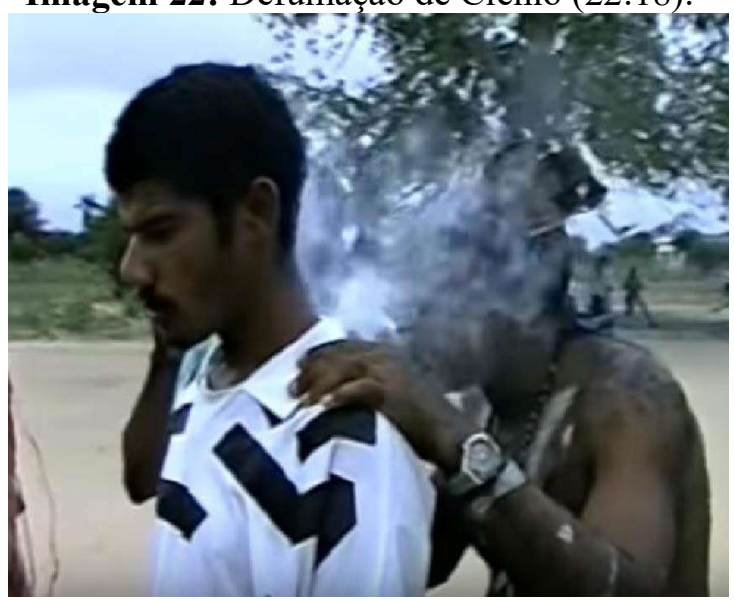

Fonte: Amorim (2001).

Pela primeira vez no ritual, o pagante da promessa se encontra no centro do Terreiro junto a dois Praiás, que seguram lanças coloridas, atrás do Cantador (imagem 21). Todo o conjunto de participantes percorre o espaço ritual, finalizando o caminhar, segundo informado no etnodocumentário, com a "consagração de Clênio pelos Praiás" (AMORIM, 2001). Nesse momento, imagem 22, sob as Toantes, os Praiás e Cantadores "encruzam" Clênio e o Pajé o defuma com a fumaça do seu Campiô.

As Gaitas são tocadas enquanto os indígenas apresentam um semblante de respeito pela finalização do ritual. O cortejo conclui a consagração do pagante da promessa e segue pelo Terreiro, até o entardecer quando finalizam o evento e retornam ao Poró. No ambiente onde descansam, os moços retiram as vestes dos Praiás e as levam para o Poró onde são guardadas. Penduradas as indumentárias pelos fios de Caroá, o local é fechado e encerrado pagamento da promessa.

\section{Considerações finais}

Não tivemos o objetivo de enfocar detalhes da etnia Karuazu nesta produção, mas apresentar e elaboração da imagem étnica, realizada pelos indígenas, através do universo religioso dos Praiás e Encantados. Essa (re)elaboração é compartilhada entre as etnias do Sertão, pois os Praiás e seus rituais passaram, principalmente no início do século XXI, a ser os argumentos base das identidades defendidas pelos Jiripankó, Kalankó, Katokinn, Karuazu, Koiupanká e Pankararu, possibilitando-Ihes o 
reconhecimento pelo Estado e o acesso a alguns dos direitos previstos na Constituição Federal de 1988.

A partir da promessa de Clênio e de outros rituais realizados entre os anos 1992 e 2001 houve a consolidação desses grupos étnicos e da rede de relações que mantêm ainda na atualidade; com esse processo, buscaram se fortalecer nas reinvindicações ao assumirem os rituais e alianças enquanto estratégias durante e após os reconhecimentos. Nas relações interétnicas que compartilham, os eventos religiosos representam a prática de costumes que foram ressignificados do passado vivenciado pelos ancestrais em Brejo dos Padres, sendo associados à sua crença cosmológica e fé nas divindades da tradição, principalmente no caso dos Pratos oferecidos aos Praiás.

Ao apresentarem ao público seus costumes, por meio dos registros imagéticos do Antropólogo Siloé Amorim e alguns outros posteriores, os grupos étnicos, visaram defender seus lugares sociais enquanto ramas de Pankararu e possibilitar as suas autonomias enquanto povos emergentes do silêncio ocorrido desde os anos 1890. Por fim, compreendemos as culturas dessas populações do Sertão alagoano, enquanto resultados de processos históricos, permeados pelas escolhas e vivências dos seus ancestrais, sendo os rituais, como o analisado, representações desses processos. 
Espaço Ameríndio

\section{Referências bibliográficas}

AMORIM, Siloé Soares de. Resistência e ressurgência indígena no alto sertão alagoano. Maceió: Iphan - AL, 2017.

AMORIM, Siloé Soares de. A promessa de Clênio Karuazu: por uma graça alcançada. Pariconha-AL. Antropologia Visual em Alagoas - AVAL, 2001.

ARRUTI, José Maurício Andion. O Reencantamento do mundo: trama histórica e arranjos territoriais Pankararu. 2002. 219 f. Dissertação (Mestrado em Antropologia Social) - PPGAS, UFRJ/MN, Rio de Janeiro, RJ, 1996.

ARRUTI, José Maurício Andion. A árvore Pankararu: fluxos e metáforas da emergência étnica no sertão do São Francisco. In: OLIVEIRA, João Pacheco de (org.). A viagem de volta: etnicidade, política e reelaboração cultural no Nordeste indígena. $2^{\mathrm{a}}$ ed. Rio de Janeiro: Contra Capa/LACED, 2004. p. 231-280.

BARRETO, Juliana Nicolle. Corridas do Umbú: rituais e imagens entre os Índios Karuazu. 2010. 169 f. Dissertação (Mestrado em Antropologia) - PPGA, UFPE, Recife, PE, 2010.

BRITO, Maria de Fátima. Relatório Antropológico da terra Indígena Geripancó. Recife: Fundação Nacional do Índio - FUNAI, 1992.

CANDAU, Joel. Memória e identidade. São Paulo: Contexto, 2016.

GUEIROS, Lucas Emanoel Soares. Os Jiripankó e o ritual Menino do Rancho: cosmologia, identidade e memória indígena. 2017. 74 f. Monografia (Conclusão de Curso em História) - UNEAL, Palmeira dos Índios, AL, 2017.

GINZBURG, Carlo. Mitos, emblemas e sinais: morfologia e história. São Paulo: Companhia das Letras. 1989.

HERBETTA, Alexandre. “A idioma” dos índios Kalankó - uma etnografia da música no alto sertão alagoano. 2006. 204 f. Dissertação (Mestrado em Antropologia Social) PPGAS, UFSC, Florianópolis, SC, 2006.

LARAIA, Roque de Barros. Cultura: um conceito antropológico. Rio de Janeiro: Jorge Zahar Ed, 2001.

MATTA, Priscila. Dois elos da mesma corrente: uma etnografia da corrida do Imbu e da Penitência entre os Pankararu. 2005. 204 f. Dissertação (Mestrado em Antropologia Social) - PPGAS, USP, São Paulo, SP, 2005.

MAUSS, Marcel. Sociologia e Antropologia. Editora: EDUSP. São Paulo, 1974.

MENDONÇA, Vinícius Alves de. Costumes e identidades: estudos sobre os grafismos corporais Jiripankó. Sobre Ontens, v. 2, p. 269 - 285, jul./dez. 2019. 
MURA, Claudia. "Todo mistério tem dono!" Ritual, política e tradição de conhecimento entre os Pankararu. 2012. 339 f. Tese (Doutorado em Antropologia Social) - PPGAS, UFRJ/MN, Rio de Janeiro, RJ, 2012.

OLIVEIRA, João Pacheco de. Uma etnologia dos "índios misturados"? Situação colonial, territorialização e fluxos culturais. In: OLIVEIRA, João Pacheco de (org.). A viagem de volta: etnicidade, política e reelaboração cultural no Nordeste indígena. $2^{\mathrm{a}}$ ed. Rio de Janeiro: Contra Capa/LACED, 2004. p. 13-42.

OLIVEIRA, Roberto Cardoso de. O trabalho do antropólogo. São Paulo: UNESP, 2000.

PEIXOTO, José Adelson Lopes. Minha identidade é meu costume: religião e pertencimento entre os indígenas Jiripankó - Alagoas. 2018. 204 f. Tese (Doutorado em Ciências da Religião). PPGCR, UNICAP, Recife, PE, 2018.

POMPA, Cristina. História de um desaparecimento anunciado: as aldeias missionárias do São Francisco, XVIII - XIX. In: OLIVEIRA, João Pacheco (org.). Uma presença indígena no Nordeste: processos de territorialização, modos de reconhecimento e regimes de memória. Rio de Janeiro: Contra Capa, 2011. p. 267-292.

RODRIGUES, Yuri Franklin dos Santos; Mendonça, Vinícius Alves de. Menino do Rancho entre os índios Jiripankó, Pariconha, Al: Ritual, atores e alianças. Anais do V ENHS - Encontro Nacional de História do Sertão. Delmiro Gouveia-AL: UFAL, 2018, p. $1-16$.

SAMAIN, Etienne. As imagens não são bolas de sinuca. Como pensam as imagens. In: SAMAIN, Etienne. Como pensam as imagens. Campinas-SP: Editora da Unicamp, 2012.

SANTOS, Cícero Pereira dos. Território e identidade: processo de formação do povo indígena Jiripancó. 2015. 67 f. Monografia (Conclusão de Curso em História) - UNEAL, Palmeira dos Índios, AL, 2015.

Recebido em: 10/05/2020 * Aprovado em: 11/10/2020 * Publicado em: 16/12/2020 